\title{
Microwave Mediated Synthesis of Novel 1,3,5- Triazine Derivative and their Biological Evaluation
}

\author{
Krishn Kumar Barmase ${ }^{1 *}$, Deepak Basedia ${ }^{2}$, Balkrishna Dubey ${ }^{3}$ \\ ${ }^{1,2,3}$ Department of Pharmaceutical Chemistry, Technocrats Institute of Technology-Pharmacy, Bhopal, India \\ *Corresponding author: krishnbarmase555@gmail.com
}

\begin{abstract}
Triazine derivative are synthesized by replacement of chloride ions of Cyanuric chloride and 1,3,5Triazine derivative are showing promising biologically activity such as Antibacterial, Antifungal, Antimalarial, Antivirus, Anticancer that's why interest of researches on synthesis of 1,3,5Triazine derivatives always in focused. The present study reported the synthesis of 2,4,6-Trisubstituted 1,3,5-Triazine derivatives by Microwave mediated Method which gave the desired result in less time with higher yield. The structure of 1,3,5-Triazine derivatives have been elucidated by Spectral of IR, NMR and MASS. The derivative of 1,3,5-Triazine are evaluated for their In vitro Antibacterial activity against Gram Positive and Gram Negative Bacterial species and shown good Antibacterial effect.
\end{abstract}

Keywords: Antibacterial activity, Microwave irradiation, 1,3,5Triazine.

\section{Introduction}

Triazine is a class of nitrogen containing heterocyclic. They have a planar six-member benzene ring like structure with three carbons replaced with nitrogen. The three isomers of Triazine are distinguished from each other by the positions of their nitrogen atoms, and are referred to as 1,2,3-Triazine, 1,2,4Triazine and 1,3,5-Triazine. 1,3,5-Triazine, also called the $\mathrm{S}$ Triazine, attracted many researches, as its symmetrical structure facilitates to synthesize diverse set of analogue as 2,4,6-mono, di or tri-substituted, symmetrical and nonsymmetrical compounds bearing different substituent.

Nitrogen atoms, and are referred to as 1,2,3-Triazine, 1,2,4Triazine and 1,3,5-Triazine. 1,3,5-Triazine, also called the STriazine, attracted many researches, as its symmetrical structure facilitates to synthesize diverse set of analogue as 2,4,6-mono, di or tri-substituted, symmetrical and nonsymmetrical compounds bearing different substituent.

Its analogues, melamine, cyanuric acid and cyanuric chloride are important starting compounds for various materials with wide range of applications in development of pharmaceuticals, textile, plastic and rubber industries. These compounds are also used as pesticides, dyestuffs, optical bleaches, explosives and surface active agents.

1,2,3-Triazine derivatives are the new member of heterocyclic compounds. In older literature, Vtriazine or $\beta$ triazine are also found along with 1,2,3-triazine isomer ${ }^{1}$. Heterocyclic moiety fused with 1,2,3- triazine-4-ones show high chemically-reactivity and biological activity ${ }^{2}$. As a comparison with 1,2,4- and 1,3,5-triazine isomers, the 1,2,3triazine isomer is the least studied isomer because the nucleus of 1,2,3-triazine isomer is the least stable as compare to rest isomers and synthetic routes are also limited ${ }^{3}$. Newly discovered 1,2,3-triazines are more effective drugs along with less adverse effects. Tubercidin, toyocamycin, sangivamycin, 2-azaadenosine and 2- aza-2-desamino-5,8-dideazafolic acid are the 1,2,3- triazine moiety containing drugs which show different pharmacological activities.

\section{Methodology and Experiment}

It has been known that amines react with cyanuric chloride, providing access to amine-functionalized 1,3,5-triazine compounds.

Replacement of one, two or all the three chlorine atoms of the 2,4,6-trichloro-s-triazine by amino group depends upon the reaction temperature. Mono amination takes place at $0-15^{\circ} \mathrm{C}$, Diamination at $20-50^{\circ} \mathrm{C}$ and Triamination at $80-100^{\circ} \mathrm{C}$, depending upon the nucleophilic character of the solvent and the amine.

Microwave synthesis represents a major breakthrough in synthetic chemistry methodology; a dramatic change in the way chemical synthesis is performed. Conventional heating, long known to be inefficient and time consuming, has been recognized to be creatively limiting too. Microwave synthesis gives the chemists more time to expand their creativity, test new theories and develop new processes. Instead of spending hours or even days synthesizing a single compound, chemists can now perform the same reaction in minutes. The problem associated with waste disposal of solvents has been overcome by performing reactions without a solvent under microwave irradiation. Coupling of microwave irradiation with the use of mineral-supported catalysed reactions, under solvent-free conditions, provides clean chemical processes with the advantage of enhanced reaction rates, higher yields, greater selectivity, and greater ease of manipulation. Thus microwave synthesis acts as a potential tool for green chemistry. 
A. Scheme of Work

The synthetic scheme includes following steps.

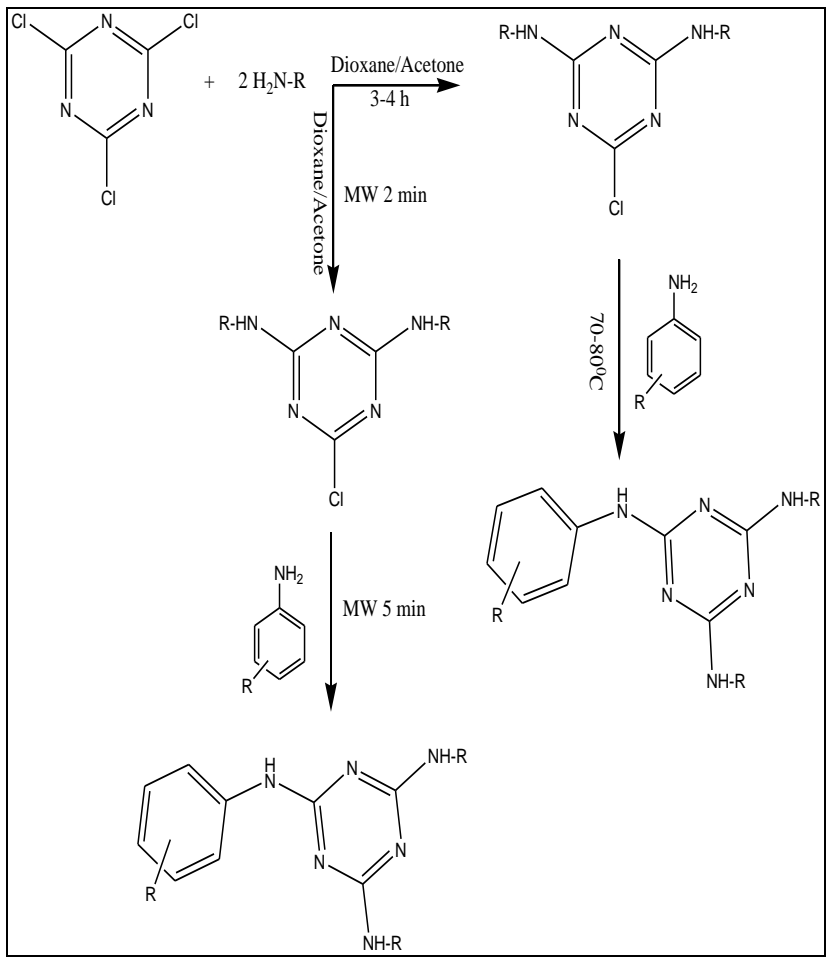

\section{B. Chemical and Equipment}

Cyanuric chloride was procured from Avra Chemicals, aniline, acetone, 1,4-dioxane, sodium carbonate, diethylamine, diphenylamine, morpholine, 2-nitroaniline, 3-nitroaniline, 4nitroaniline, hydrochloric acid, ethanol, sodium hydroxide, chloroform and all other chemicals used were of analytical or synthetic grade and purchased from Oxford Fine Chemicals. All the chemicals were used as received without any further purification.

Digital balance (Wesar), Heating mantle (Biotechnic), domestic microwave (Bajaj) were used during the study.

Purity of compound is determined by TLC and Rf value of compound has determine by using solvent system Hexane, Acetic acid, Acetone. Solubility of synthesized compound has determined using different solvent system Water, Ethanol, Chloroform, DMSO.

The spectral characteristics were used to elucidate the structures of the synthesized compounds. The purity and homogeneity of the synthesized compounds was confirmed by single spots on the TLC plate. Spectral analyses (IR, NMR \& Mass) of the compounds satisfactorily supported the structures of the synthesized compounds.

\section{Experimental Procedure}

1) Experimental Procedures (Conventional Synthesis)

The experimental scheme was adapted from the reports of Solanki and Tailor and optimized to the conditions of the laboratory. The scheme involved nucleophilic substitution of cyanuric chloride in successive steps to yield the desired compounds. The steps involved in the reaction protocol are presented in figure 1 .

a) Synthesis of 4,6-dichloro-N,N-diethyl-1,3,5-triazin-2amine:

Diethylamine $(0.01 \mathrm{~mol}, 0.73 \mathrm{~g}(1.02 \mathrm{~mL})$ in $10 \mathrm{~mL}$ acetone $)$ was added slowly to cyanuric chloride $(0.01 \mathrm{~mol}, 1.845 \mathrm{~g}$ in $30 \mathrm{~mL}$ acetone) with constant stirring for 5 hours at 0 to $5^{\circ} \mathrm{C}$. Intermittently, sodium carbonate solution $(0.005 \mathrm{~mol}, 0.53 \mathrm{~g}$ in $10 \mathrm{~mL}$ water) was added drop wise to neutralize the $\mathrm{HCl}$ evolved over the course of the reaction. The progress of the reaction was monitored by TLC. The content of the flask was poured into crushed ice and the solid that separated out was filtered, washed with water, dried and recrystallised from alcohol to give the 4,6-dichloro-N,N-diethyl-1,3,5-triazin-2amine.

b) Synthesis of 6-chloro- $N^{2}, N^{2}, N^{4}, N^{4}$-tetraethyl-1,3,5triazine-2,4-diamine:

Diethylamine $(0.01 \mathrm{~mol}, 0.73 \mathrm{~g}(1.02 \mathrm{~mL})$ in $10 \mathrm{~mL}$ acetone $)$ was added slowly to the 4,6-dichloro-N,N-diethyl-1,3,5-triazin2-amine (0.01 mol, $2.21 \mathrm{~g}$ in $35 \mathrm{~mL}$ acetone) with constant stirring for 7.5 hours at room temperature. Intermittently, sodium carbonate solution $(0.005 \mathrm{~mol}, 0.53 \mathrm{~g}$ in $10 \mathrm{~mL}$ water $)$ was added drop wise to neutralize the $\mathrm{HCl}$ evolved over the course of the reaction. The progress of the reaction was monitored by TLC. The content of the flask was poured into crushed ice and the solid that separated out was filtered, washed with water, dried and recrystallised from alcohol to give the 6chloro- $N^{2}, N^{2}, N^{4}, N^{4}$-tetraethyl-1,3,5-triazine-2,4-diamine.

c) General procedure for synthesis of target compounds:

Aromatic amine $(0.01 \mathrm{~mol})$ and 6-chloro- $N^{2}, N^{2}, N^{4}, N^{4}$ tetraethyl-1,3,5-triazine-2,4-diamine. $(0.01 \mathrm{~mol})$ were dissolved in acetone $(40 \mathrm{~mL})$. The reaction mixture was refluxed for 8 hours. Intermittently, sodium carbonate solution (0.005 mol, $0.53 \mathrm{~g}$ in $10 \mathrm{~mL}$ water) was added drop wise to neutralize the $\mathrm{HCl}$ evolved over the course of the reaction. The progress of the reaction was monitored by TLC. The content of the flask was poured into crushed ice and the solid that separated out was filtered, washed with water, dried and recrystallised from alcohol to give the target compound.

2) Experimental Procedures (Microwave assisted synthesis)

a) Synthesis of 4,6-dichloro-N,N-diethyl-1,3,5-triazin-2amine:

To a $50 \mathrm{~mL}$ round bottom flask was added $1.8 \mathrm{~g}(0.01 \mathrm{~mol})$ cyanuric chloride, $15 \mathrm{~mL}$ of 1,4-dioxane, $4.5 \mathrm{~mL}$ DMF, $2.5 \mathrm{~g}$ sodium hydrogen carbonate, and $0.01 \mathrm{~mol}$ diethylamine. The flask was kept in microwave oven and irradiated for 6 min at low power. The content of the flask was poured into crushed ice and the solid that separated out was filtered, washed with water, dried and recrystallised from alcohol to give 4,6-dichloro-N,Ndiethyl-1,3,5-triazin-2-amine.

b) Synthesis of 6-chloro- $N^{2}, N^{2}, N^{4}, N^{4}$-tetraethyl-1,3,5triazine-2,4-diamine:

To a $50 \mathrm{~mL}$ round bottom flask was added $2.21 \mathrm{~g}(0.01 \mathrm{~mol})$ 
4,6-dichloro-N,N-diethyl-1,3,5-triazin-2-amine, $15 \mathrm{~mL}$ of 1,4dioxane, $4.5 \mathrm{~mL}$ DMF, $2.5 \mathrm{~g}$ sodium hydrogen carbonate, and 0.01 mol diethylamine. The flask was kept in microwave oven and irradiated for $2.5 \mathrm{~min}$ at low power. The content of the flask was poured into crushed ice and the solid that separated out was filtered, washed with water, dried and recrystallised from alcohol to give 6-chloro- $N^{2}, N^{2}, N^{4}, N^{4}$-tetraethyl-1,3,5-triazine2,4-diamine.

c) General procedure for synthesis of target compounds:

To a $50 \mathrm{~mL}$ round bottom flask was added $2.58 \mathrm{~g}(0.01 \mathrm{~mol})$ 6-chloro- $N^{2}, N^{2}, N^{4}, N^{4}$-tetraethyl-1,3,5-triazine-2,4-diamine, 15 $\mathrm{mL}$ of 1,4-dioxane, $4.5 \mathrm{~mL}$ DMF, $2.5 \mathrm{~g}$ sodium hydrogen carbonate, and $0.01 \mathrm{~mol}$ of aromatic amine. The flask was kept in microwave oven and irradiated for $3 \mathrm{~min}$ at low power. The content of the flask was poured into crushed ice and the solid that separated out was filtered, washed with water, dried and recrystallised from alcohol to give the target compounds

Table 1

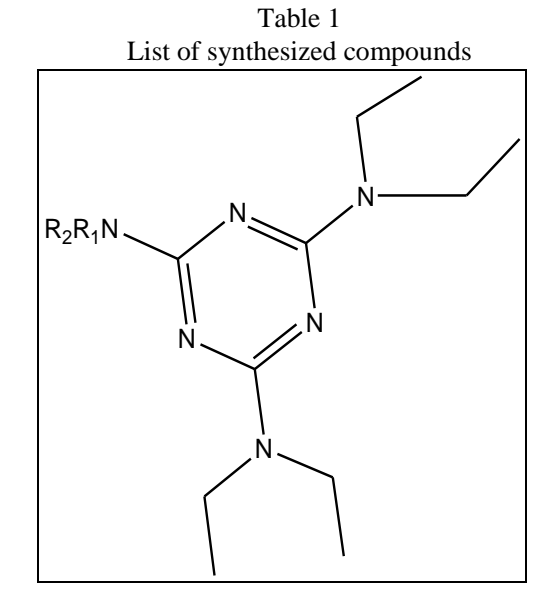

\begin{tabular}{|l|l|}
\hline Code & \\
\hline & \\
\hline$T Z 1$
\end{tabular}

D. Spectral Studies

1) $N^{2}, N^{2}, N^{4}, N^{4}$-tetraethyl- $N^{6}, N^{6}$-diphenyl-1,3,5-triazine2,4,6-triamine, $T Z 1$

${ }^{1} \mathrm{H}$ NMR Spectra $\left(\delta, 300 \mathrm{MHz}, \mathrm{CDCl}_{3}\right): 6.823-7.916(\mathrm{CH}-$ Benzene), $2.995\left(\mathrm{CH}_{2}\right), 1.592\left(\mathrm{CH}_{3}\right)$, IR (KBr): $3000-2900 \mathrm{~cm}^{-}$
1 (C-C cyclic), $1600-1700 \mathrm{~cm}^{-1}$ (C-C Ar), 3100-3000 cm ${ }^{-1}$ (CH Ar), $1500 \mathrm{~cm}^{-1}(\mathrm{C}=\mathrm{N}), 1400-1000 \mathrm{~cm}^{-1}(\mathrm{C}-\mathrm{N})$

Mass - 390 (Calculated); 384.8

2) $N^{2}, N^{2}, N^{4}, N^{4}$-tetraethyl- $N^{6}, N^{6}$-dimethyl-1,3,5-triazine2,4,6-triamine, $T Z 2$

${ }^{1} \mathrm{H}$ NMR Spectra $\left(\delta, 300 \mathrm{MHz}, \mathrm{CDCl}_{3}\right): 3.190\left(\mathrm{~N}^{-\mathrm{CH}_{3}}\right)$, 2.538-2.496( $\left(\mathrm{CH}_{2}\right), 1.590\left(\mathrm{CH}_{3}\right)$

IR (KBr): 3000-2900 cm-1 (C-C cyclic), 1600-1700 $\mathrm{cm}^{-1}$ (CC Ar), 3100-3000 cm $\mathrm{cm}^{-1}$ (CH Ar), $1500 \mathrm{~cm}^{-1}(\mathrm{C}=\mathrm{N}), 1400-1000$ $\mathrm{cm}^{-1}(\mathrm{C}-\mathrm{N})$

Mass - 266 (calculated); 269.2

3) $N^{2}, N^{2}, N^{4}, N^{4}$-tetraethyl- $N^{6}-(2-$ nitrophenyl)-1,3,5-triazine2,4,6-triamine, $T Z 3$

${ }^{1} \mathrm{H}$ NMR Spectra $\left(\delta, 300 \mathrm{MHz}, \mathrm{CDCl}_{3}\right): 8.025-6.833(\mathrm{CH}-$ Benzene), $3.974(\mathrm{~N}-\mathrm{H}), 2.991\left(\mathrm{CH}_{2}\right), 1.560\left(\mathrm{CH}_{3}\right)$

IR (KBr): $3000-2900 \mathrm{~cm}^{-1}$ (C-C cyclic), $1600-1700 \mathrm{~cm}^{-1}$ (CC Ar), 3100-3000 $\mathrm{cm}^{-1}$ (CH Ar), $1500 \mathrm{~cm}^{-1}(\mathrm{C}=\mathrm{N}), 1400-1000$ $\mathrm{cm}^{-1}(\mathrm{C}-\mathrm{N}), 1350(\mathrm{~N}-\mathrm{O})$

Mass - 359 (Calculated); 360.1

4) $N^{2}, N^{2}, N^{4}, N^{4}$-tetraethyl- $N^{6}$-(3-nitrophenyl)-1,3,5-triazine2,4,6-triamine, TZ4

${ }^{1} \mathrm{H}$ NMR Spectra $\left(\delta, 300 \mathrm{MHz}, \mathrm{CDCl}_{3}\right): 7.913-6.828(\mathrm{C}-\mathrm{H}$ aromatic), $4.010(\mathrm{~N}-\mathrm{H}), 2.996\left(\mathrm{CH}_{2}\right), 1.562\left(\mathrm{CH}_{3}\right)$

IR (KBr): 3000-2900 cm-1 (C-C cyclic), $1600-1700 \mathrm{~cm}^{-1}$ (CC Ar), 3100-3000 $\mathrm{cm}^{-1}$ (CH Ar), $1500 \mathrm{~cm}^{-1}(\mathrm{C}=\mathrm{N}), 1400-1000$ $\mathrm{cm}^{-1}(\mathrm{C}-\mathrm{N}), 1350(\mathrm{~N}-\mathrm{O})$

Mass - 359 (Calculated); 360.1

5) $N^{2}, N^{2}, N^{4}, N^{4}$-tetraethyl- $N^{6}$-(4-nitrophenyl)-1,3,5-triazine2,4,6-triamine, $T Z 5$

${ }^{1} \mathrm{H}$ NMR Spectra $\left(\delta, 300 \mathrm{MHz}, \mathrm{CDCl}_{3}\right): 8.037-6.849(\mathrm{CH}-$ Benzene), $3.985(\mathrm{~N}-\mathrm{H}), 3.006\left(\mathrm{CH}_{2}\right), 1.283\left(\mathrm{CH}_{3}\right)$

IR (KBr): $3000-2900 \mathrm{~cm}^{-1}$ (C-C cyclic), $1600-1700 \mathrm{~cm}^{-1}$ (CC Ar), 3100-3000 $\mathrm{cm}^{-1}$ (CH Ar), $1500 \mathrm{~cm}^{-1}(\mathrm{C}=\mathrm{N}), 1400-1000$ $\mathrm{cm}^{-1}(\mathrm{C}-\mathrm{N}), 1350(\mathrm{~N}-\mathrm{O})$

Mass - 359 (Calculated); 360.1

\section{E. Physical Characteristic}

Table 2 shows the properties of the synthesized compound.

\section{Biological Evaluations}

\section{A. Antibacterial Activity}

The antibacterial action of the synthesized compounds (obtained by microwave synthesis) was evaluated against two gram positive (Proteus mirabilis and Bacillus subtilis) and two gram negative bacteria (Pseudomonas aeruginosa and Staphylococcus aureus).

Table 2

\begin{tabular}{|c|c|c|c|c|c|c|c|c|}
\hline \multirow{3}{*}{$\begin{array}{l}\text { Compound } \\
\text { Code }\end{array}$} & \multirow{3}{*}{$\begin{array}{c}\text { Molecular } \\
\text { Formula }\end{array}$} & \multirow{3}{*}{$\begin{array}{c}\text { Molecular } \\
\text { Weight }\end{array}$} & \multirow{2}{*}{\multicolumn{2}{|c|}{ Yield (\%) }} & \multirow{3}{*}{$\begin{array}{l}\text { Melting } \\
\text { Point }\end{array}$} & \multirow{3}{*}{$\begin{array}{c}\text { RF } \\
\text { Value }\end{array}$} & \multirow{3}{*}{ Colour } & \multirow{3}{*}{$\begin{array}{l}\text { Log P } \\
\text { Value }\end{array}$} \\
\hline & & & & & & & & \\
\hline & & & $\begin{array}{c}\text { Conventional } \\
\text { Method }\end{array}$ & $\begin{array}{c}\text { Microwave } \\
\text { method }\end{array}$ & & & & \\
\hline TZ1 & $\mathrm{C}_{23} \mathrm{H}_{30} \mathrm{~N}_{6}$ & 390.52 & 32 & 67 & 260 & 0.67 & Yellow & 6.01 \\
\hline TZ2 & $\mathrm{C}_{13} \mathrm{H}_{26} \mathrm{~N}_{6}$ & 266.38 & 29 & 62 & 174 & 0.59 & Brown & 3.56 \\
\hline TZ3 & $\mathrm{C}_{17} \mathrm{H}_{25} \mathrm{~N}_{7} \mathrm{O}_{2}$ & 359.43 & 37 & 79 & 180 & 0.53 & Yellow & 2.87 \\
\hline TZ4 & $\mathrm{C}_{17} \mathrm{H}_{25} \mathrm{~N}_{7} \mathrm{O}_{2}$ & 359.43 & 34 & 81 & 169 & 0.64 & Yellow & 2.91 \\
\hline TZ5 & $\mathrm{C}_{17} \mathrm{H}_{25} \mathrm{~N}_{7} \mathrm{O}_{2}$ & 359.43 & 39 & 82 & 157 & 0.66 & Yellow & 2.92 \\
\hline
\end{tabular}


Table 3

MIC of the synthesized compounds against gram positive and gram negative bacteria

\begin{tabular}{|l|l|l|l|l|}
\hline \multirow{2}{*}{ Code } & \multicolumn{4}{|c|}{ MIC $(\mu \mathrm{g} / \mathrm{mL})^{\mathrm{a}, \mathrm{b}, \mathrm{c}}$} \\
\cline { 2 - 5 } & P. mirabilis & B. subtilis & P. aeuroginosa & S. aureus \\
\hline TZ1 & 25 & 25 & 25 & 25 \\
\hline TZ2 & 25 & 25 & 25 & 25 \\
\hline TZ3 & 12.5 & 6.25 & 12.5 & 6.25 \\
\hline TZ4 & 12.5 & 6.25 & 6.25 & 6.25 \\
\hline TZ5 & 12.5 & 6.25 & 6.25 & 6.25 \\
\hline Norfloxacin & 2.56 & 1.28 & 1.28 & 1.28 \\
\hline
\end{tabular}

The synthesized triazine derivatives were dissolved in dimethyl sulfoxide (DMSO) and the further dilutions of the test compounds were prepared at the required quantities of 100,50 , $25,12.5$ and $6.25 \mu \mathrm{g} / \mathrm{mL}$ concentrations with Mueller-Hinton broth medium.

Overnight culture of all four bacteria were prepared separately in nutrient broth, and used as a microbial source for the determination of MIC.

The sterile capped test tubes were numbered from 1 to 8 and all of the steps were carried out using aseptic technique. $10 \mathrm{ml}$ of drug sample solution was added to the first tube while $2.0 \mathrm{ml}$ of nutrient broth to all other tubes. Transferred $2.0 \mathrm{ml}$ from the first tube to the second tube. Using a separate pipette, mixed the contents of this tube and transferred $2.0 \mathrm{ml}$ to the third tube. Continue dilutions in this manner to tube number 8 , being certain to change pipettes between tubes to prevent carryover of antibiotic on the external surface of the pipette. Removed 2.0 $\mathrm{ml}$ from tube 8 and discard it. The $9^{\text {th }}$ tube, which serves as a control, receives no drug sample. Norfloxacin $(10 \mu \mathrm{g} / \mathrm{ml})$ was used as standard drug. Suspended to an appropriate turbidity several colonies of the culture to be tested in $5.0 \mathrm{ml}$ of nutrient broth to give a slightly turbid suspension. Added $0.2 \mu 1$ of the diluted culture suspension to each of the tubes. The final concentration of drug sample is now one-half of the original concentration in each tube. Incubated all tubes at $37^{\circ} \mathrm{C}$ overnight. Examined tubes for visible signs of bacterial growth.

The highest dilution without growth is the minimal inhibitory concentration (MIC). The antibacterial activity of the synthesized compounds was evaluated at various concentrations to determine the MIC of each compound.

${ }^{\mathrm{a}} \mathrm{A}$ set of tubes with only the inoculated broth was used as control to determine MIC

${ }^{\mathrm{b}} \mathrm{MIC}$ is expressed by measuring the turbidity of test and control dilution tubes. A 50\% decrease in turbidity was taken as MIC.

${ }^{c}$ All values are expressed as mean of a set of three experiments

\section{Result and Discussion}

In the present work, 2,4,6-trisubstituted 1,3,5-triazine analogs were synthesized using the nucleophilic substitution on cyanuric chloride in presence of dioxane or acetone. The microwave energy was applied for 1 minute for 2 times.

In present work we apply Green synthesis of 1,3,5- Triazines were synthesized in satisfactory using microwave assisted method. The compounds were found to be of better purity and yield as compared to the conventional synthetic procedure. The compounds shown good antibacterial potential against both gram negative and gram positive bacterium. In the present work was able to device a green, efficient method for the synthesis of substituted 1,3,5- triazines.

Five derivative of 1,3,5-Triazine were synthesized and confirmed by physical and spectral analysis. The synthesized compounds were characterized by IR, ${ }^{1} \mathrm{HNMR}$ and Mass spectral data. All the synthesized compounds show characteristic absorption peaks in IR and NMR spectra.

The antimicrobial potential of the synthesized compounds has been evaluated by determining the minimum inhibition concentration values by broth dilution method using MuellerHinton broth for culturing the pathogen. The results obtained indicate that the presence of $\mathrm{NO}_{2}$ functional group in the compounds was beneficial for the antibacterial potential.

The sequential replacement of three chloride atoms on cyanuric chloride with different nucleophiles provides the synthesis of a variety of substituted 1,3,5-Triazine molecules. In light of its operational simplicity and efficiency, this reliable method is expected to have a broad utility due to the scope of applications of the 1,3,5-Triazines. Antibacterial activity of the newly compounds were investigated.

The present review aims to serve as a background for the research in this area.

\section{Conclusion}

This paper presented an overview on microwave mediated synthesis of novel 1,3,5-Triazine derivative and their biological evaluation.

\section{Acknowledgement}

The authors are thankful to Technocrats T.I.T. group of Institution, Bhopal (M.P.) for providing the necessary facilities and requirements for completing the research work.

\section{References}

[1] Basedia, D.K., Shrivastava, B., Dubey, B.K. and Sharma, P. 2014. Synthesis, characterization and antimicrobial activity of novel 2,5substituted aryl-7-phenyl-1,3,4-oxadiazolo-[3,2-a]-1,3,5-triazine derivatives. International Journal of Biomedical Research. 5, 1 (Jan. 2014), 13-18.

[2] A. Solankee,; K Patel; R Patel,; A Facile Synthesis and Studies of Some New Chalcones and Their Derivatives Based on Heterocyclic Ring, E Journal of Chemistry. 2012, 9, 1897-1905

[3] S. S. Chobe, et al; An efficient synthesis and in vitro antimicrobial activity of 1, 2, 4-Triazin-6-(5H)-one derivatives, Pelagia Research Library, Der Chemica Sinica. 2010, 1(2), $86-90$. 
[4] Yin Lei,; Zhi Cui Yue, et al; Chinese Chemical Letters, 2005, 16 (06), 739 -742 .

[5] Zhongyi He,; Liping Xiong, et al; Chinese Science Bulletin, 2005, 50 (12), 1174 - 1179Biesele, J.J.; Cancer. 1952, 5, 787-791.

[6] M.F.G. Stevens,; G.P.Ellis,; G.B West,.; Progress in Medicinal Chemistry, North Holland, Amsterdam, 1976, pp. 205-269.

[7] R. N. Butler,; , A.M Fahy; Tetrahedron Letters. 2006, 47, 1721-1724.

[8] J.K. Simons; M.R.Saxton; Organic Syntheses. 1963, 4, 78.

[9] P.Diana,; P.Barraja,; European Journal of Medicinal Chemistry. 2002, 37 , 267-272.

[10] A.Rauf,; S.Sharma; S. Gangal; Arkivoc. 2007, 16, 137-147.

[11] J.J.Vora,; S.B.Vasava,; E-Journal of Chemistry. 2009, 6, 201-206.

[12] B.S. Dawane,; S.N. Kadam,; B.M. Shaikh,.; Der Pharmacia Lettre. 2010, $2,126-131$

[13] C.A.M. Afonso,; N.M.T. Lourenco,; Molecules. 2006, 11, 81-102.

[14] A. Hassner,; I. Namboothiri,; Organic Syntheses Based name reactions. Elsevier, 2012, pp. 46-47.

[15] J. J. Shie; J. M Fang,; Journal of organic chemistry. 2007, 72, 3141- 3144.

[16] S. Oudir,; B. Rigo,; J. P.Henichart,; Gautret, 2006,2845.

[17] A.S. Grewal,; K. Kumar,; S. Redhu,; S. Bhardwaj,; International Research Journal of Pharmaceutical and Applied Sciences. 2013, 3, 278-285.

[18] M. S. Chande,; N Rajgopal Dravid et al.; Indian Acad. Science. 1988, 100 (01), 53- 58.

[19] Y. Miyamoto,; Hitoshi Kohno, et al.; Journal of pesticide science. $1995,20,119-128$.

[20] B. Zacharie,; D. Fortin, et al.; A journal of chemistry. 1999

[21] D. B. Lazarev,; S. M. Ramsh, et al; Publication in Russian Institute of Toxicology, 1999.

[22] Z. Pourghobadi,; F. Seyyed-Majidi, et al.; Polish Journal of chemistry. 2000, 74, $837-846$.

[23] Ho-Sang Moon,; Eric M. Jacobson, et al.; Journal of American chemical Society. $2002,124,11608-11609$
[24] T. Jacqueline,; Lee Jae Wook et al.; Journal of American chemical society. Vol 5, No- 02. 2003,117- 120.

[25] Sonya M Khersonsky,; Chang Young-Tae et al.; Journal of combinatorial chemistry, American chemical society. 2004, 6, $474-477$.

[26] V. K. Pandey,; Tusi Sarah, et al; Acta pharm. 2004, 54, 1 - 12.

[27] Shamsa Fazel,; Maliheh Barazandeh-Tehrani, et al.; Tehran university of Medical Science, Daru, 2004, 12 (02).

[28] Yue Lei, Yin;, Cui Zhi et al; Chinese Chemical Letters, 2005, 16 (06), 739 $-742$

[29] P Miladinova,; Journal of University of Chemical Technology and Metallurgy, 2006, 41(2), 147 - 152.

[30] J. A. Chaudhari,; M. V. Hathi, et al; Electronic Journal of Chemistry, 2006, 03 (13), $298-302$.

[31] A. Solankee,; K. Kapadia et al.; Indian Journal of Chemistry, 2007, 46 (b), $1707-1712$.

[32] D. M. Musatov,; D.V Kurilov,.; A.K. Rakishev, et al; Ukrainica Bioorganica Acta 1. 2008, $61-62$.

[33] B. Kolesinska; Z. J. Kamiski, et al .; Acta Poloniae Pharmaceutica - Drug Research, 2008, 65 (06), $749-751$.

[34] J. D Huang ; X.P Hu,.; Chinese Chemical Letters 19. 2008, 261 - 263.

[35] B.B. Baldaniya,; P. K.Patel,. et al; Electronic Journal of Chemistry. 2009, 6(3), $673-680$

[36] P. B Kaswala; K. H.Chikhalia, et al; ARKIVOC. 2009, 326 - 335.

[37] K. Didehban,; H. Namazi, et al; Iranian Polymer Journal 18 (9). 2009, 731 $-741$.

[38] B. M. Shaikh,.; S. S. Chobe, et al; Pelagia Research Library, Der Chemica Sinica. 2010, 1(2), $86-90$.

[39] A.Solankee,; K.Kapadia, et al; European Journal of Medicinal Chemistry 45. $2010,510-518$.

[40] S Shaikh,.; K. K. Singh, et al; Electronic Journal of Chemistry 7(4). 2010, $1396-1406$. 